\title{
Trends and predictors of mortality in unstable pelvic ring fracture: a 10-year experience with a multidisciplinary institutional protocol
}

Hsien-Te Chen ${ }^{1,2,3}$, Yu-Chun Wang ${ }^{4,5,6}$, Chen-Chou Hsieh ${ }^{4}$, Li-Ting Su ${ }^{4,6}$, Shih-Chi Wu ${ }^{4,5,6}$, Yuan-Shun Lo ${ }^{1,2,3}$, Chien-Chun Chang ${ }^{1,2,3}$ and Chun-Hao Tsai ${ }^{1,2,3,7^{*}}$ (D)

\begin{abstract}
Background: Pelvic ring fracture is often combined with other injuries and such patients are considered at high risk of mortality and complications. There is controversy regarding the gold standard protocol for the initial treatment of pelvic fracture. The aim of this study was to assess which risk factors could affect the outcome and to analyze survival using our multidisciplinary institutional protocol for traumatic pelvic ring fracture.

Material and methods: This retrospective study reviewed patients who sustained an unstable pelvic ring fracture with Injury Severity Score (ISS) $\geq 5$. All patients were admitted to the emergency department and registered in the Trauma Registry System of a level I trauma center from January 1, 2008, to December 31, 2017. The annular mortality rate after the application of our institutional protocol was analyzed. Patients with different systems of injury and treatments were compared, and regression analysis was performed to adjust for factors that could affect the rate of mortality and complications.

Results: During the 10-year study period, there were 825 unstable pelvic ring injuries, with a mean ISS higher than that of other non-pelvic trauma cases. The annual mortality rate declined from 7.8 to $2.4 \%$ and the mean length of stay was 18.1 days. A multivariable analysis showed that unstable initial vital signs, such as systolic blood pressure $<90 \mathrm{mmHg}$ (odds ratio [OR] 2.53; confidence interval [CI] 1.11-5.73), Glasgow Coma Scale < 9 (OR 3.87; Cl 1.57-9.58), 24 > ISS > 15 (OR 4.84; Cl 0.8527.65), pulse rate < 50 (OR 11.54; Cl 1.21-109.6), and diabetes mellitus (OR 3.18; Cl 1.10-9.21) were associated with higher mortality. No other specific system in the high Abbreviated Injury Scale increased the rates of mortality or complications. Conclusion: Poor initial vital signs and Glasgow Coma Scale score, higher ISS score, and comorbidity of diabetes mellitus affect the mortality rate of patients with unstable pelvic ring fractures. No single system of injury was found to increase mortality in these patients. The mortality rate was reduced through institutional efforts toward the application of guidelines for the initial management of pelvic fracture.
\end{abstract}

Keywords: Pelvic fractures, Trauma, Mortality, Risk factors, Institutional protocol, Angioembolization, Pelvic packing

\footnotetext{
* Correspondence: ritsai8615@gmail.com

'Department of Orthopedic Surgery, China Medical University Hospital,

Taichung, Taiwan

${ }^{2}$ Spine Center, China Medical University Hospital, China Medical University,

Taichung, Taiwan

Full list of author information is available at the end of the article
}

(c) The Author(s). 2019 Open Access This article is distributed under the terms of the Creative Commons Attribution 4.0 International License (http://creativecommons.org/licenses/by/4.0/), which permits unrestricted use, distribution, and reproduction in any medium, provided you give appropriate credit to the original author(s) and the source, provide a link to the Creative Commons license, and indicate if changes were made. The Creative Commons Public Domain Dedication waiver (http://creativecommons.org/publicdomain/zero/1.0/) applies to the data made available in this article, unless otherwise stated. 


\section{Introduction}

The pelvic ring, composed of the sacrum and two innominate bones and kept stable by the surrounding sacra-tuberous and sacra-spinous ligamentous structures, protects the neurovascular and hollow visceral structures of the pelvis [1]. Fracture of the pelvic ring is a relatively rare type of fracture, accounting for 1.5-3\% of cases and usually related to high energy trauma $[2,3]$. It is associated with high mortality and complication rates, and it has been termed "The Killing Fracture" [4]. The major cause of death in patients who sustained a pelvic ring fracture is massive bleeding [5].

Pelvic fractures are often linked to multiple associated injuries. Giannoudis et al. performed a study involving 11,149 patients with traumatic pelvic fracture and found that $21 \%$ and $17 \%$ of patients had severe chest trauma and head injury, respectively, both of which contributed to mortality [6]. A population-based study in Sweden revealed that traumatic brain injury, advanced age $(>70$ years), and Glasgow Coma Scale (GCS) rating $<8$ were predisposing factors to higher mortality in patients with pelvic fracture [7].

Currently, there exists some controversy regarding the lethality of pelvic fractures. Trauma patients with pelvic fractures often have multiple injuries, rendering it difficult to distinguish which predictors of mortality are related to the pelvic fracture per se or to certain associated injuries. The first aim of the present study was to identify prognostic factors and evaluate the impact of associated injuries on mortality and complications in patients with pelvic ring fractures.

A multidisciplinary team approach is critical for the management of pelvic trauma to resuscitate the patient, prevent complications, and control bleeding at the time of initial admission to the hospital. An integrated management involving a trauma surgeon, orthopedic surgeon, interventional radiologist, and intensive care unit (ICU) specialist under clinical practice guidelines was developed in the previous decades [8-16]. Black et al. [8] reported decreasing mortality rates over 13 years after initiation of a multidisciplinary institutional protocol. At present, there are no distinct, comprehensive guidelines; rather, these differ between hospital facilities and regional medical systems. In 2008, we initiated an institutional protocol for early decision-making in the treatment of pelvic fracture. The second objective of the present study was to analyze the mortality rate recorded within the previous 10 years while applying this practical guideline for traumatic pelvic ring fracture.

\section{Materials and methods} Study design

Registry-based, retrospective, observational cohort study.

\section{Data collection}

The China Medical University Hospital (Taichung, Taiwan) is a 2000-bed facility and a level I trauma center that provides $24 \mathrm{~h}$ on duty team of trauma surgeon, orthopedic surgeon, and interventional radiologist to trauma patients; it serves a population of approximately 3 million residents in central Taiwan $[17,18]$. Annually, approximately 2500 trauma patients and 600 major trauma patients with an Injury Severity Score (ISS) $\geq 16$ are hospitalized through the emergency department (ED).

This retrospective study reviewed all hospitalized patients who sustained a pelvic fracture registered in the Trauma Registry System of a level I regional trauma center from January 1, 2008, to December 31, 2017. We included only patients aged >16years who sustained trauma, and had partially stable or unstable pelvic fractures as shown through X-ray examination. The inclusion criteria included patients with a trauma International Classification of Diseases, 9th Revision, Clinical Modification code in the range of 800.0-808.9 and a calculated ISS $\geq 5$. We applied an institutional protocol involving a multidisciplinary team approach for the timely evaluation and management of patients with pelvic fracture (Fig. 1). All injury data were coded according to the 1998 version of the Abbreviated Injury Scale (AIS). Detailed patient information consisted of the following: age; sex; referral; initial GCS in the ED; vital signs upon arrival at the ED; initial resuscitation method at the ED, including airway intubation, cardiopulmonary resuscitation angiographyembolization (AE), and preperitoneal pelvic packing (PPP); AIS severity score for each body region; ISS; ED disposition (ward, ICU, operation room); hospital length of stay (LOS); LOS in ICU; diabetes mellitus (DM); and in-hospital mortality.

The first aim of this study was to analyze the initial medical parameters associated with mortality rate and complications in the hospital, including respiratory failure, pulmonary edema, adult respiratory distress syndrome, pneumonia, gastrointestinal bleeding, acute renal injury, urinary tract infection, and infection (sepsis, bacteremia, etc.). The parameters for risk assessment included initial vital signs, GCS, initial resuscitation method, ISS score, and sub score. The second aim of the study was to assess the trends in mortality over time among patients with pelvic fractures after application of the clinical practice guideline.

This study was approved by the institutional review board of the China Medical University Hospital. Since the data were analyzed anonymously, informed consent was not required.

\section{Statistical analysis}

Distributions of categorical demographics and comorbidities are presented as raw numbers and percentages 


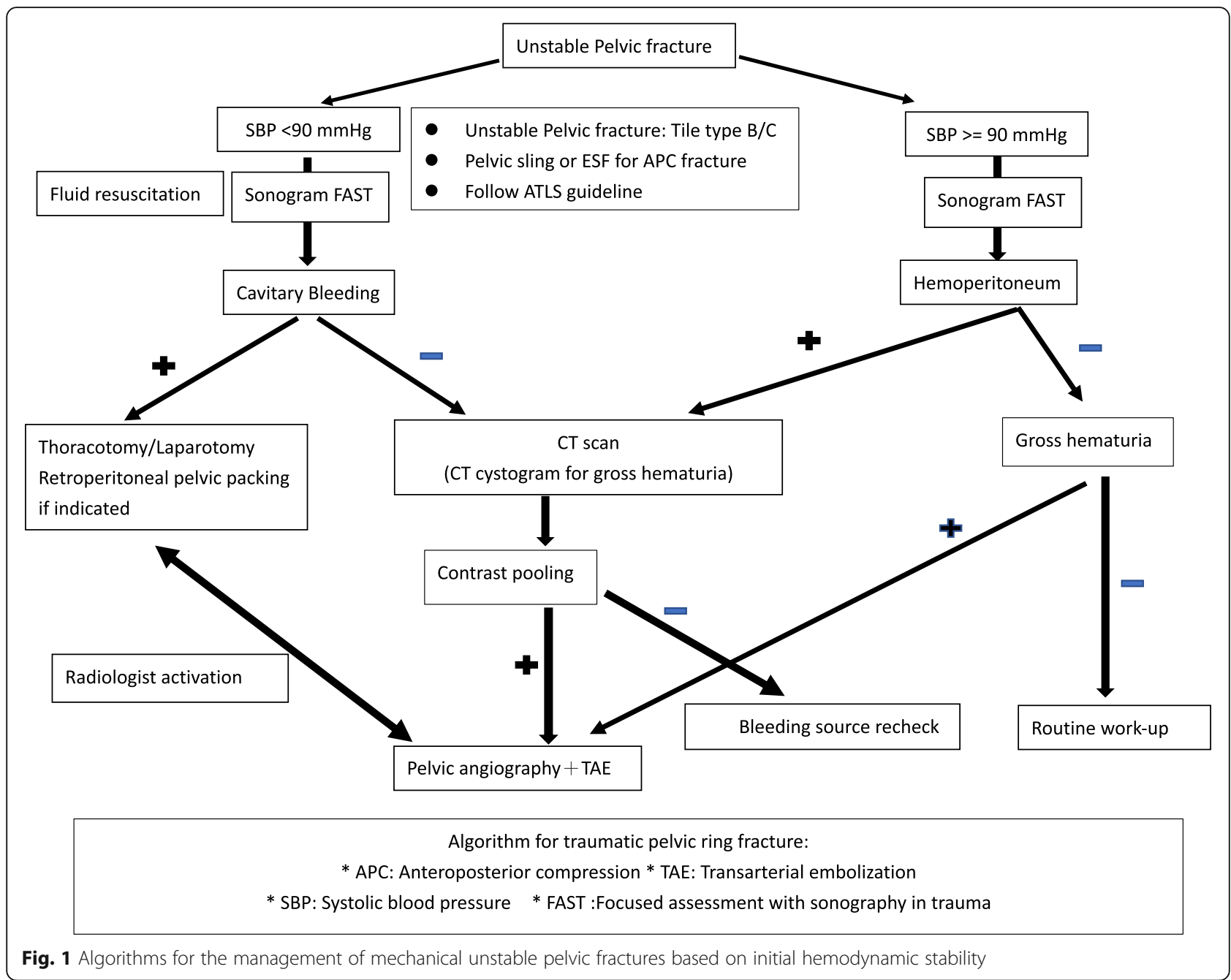

(\%). We used multiple logistic regression analysis to estimate the odds ratio (OR) and the 95\% confidence interval (CI) of mortality and complications associated with patient characteristics. Simple linear regression analysis was for initial treatment, mortality, complications, total hospital LOS (length of stay), and ICU LOS. We used the statistical package SAS version 9.4 (SAS Institute, Cary, NC, USA) to perform all data analyses. A $p$ value $<0.05$ was considered to denote statistical significance.

\section{Results}

A total of 825 patients with unstable pelvic ring injuries that met the inclusion criteria from January 1, 2008, to December 31, 2018, were enrolled out of a total database population of 21,371 patients (Table 1). All 825 patients were treated following the algorithm for traumatic pelvic ring fracture (Fig. 1). There are 400 patients of pelvic fracture with ISS $\geq 16$ included in our study group. The mean ISS of pelvic fracture patient with ISS $\geq 16$ was 27.7. The mean ISS of all patients with ISS $\geq 16$ was 21.6. Table 1 shows the characteristics of these patients.
The majority were males and middle-aged; 144 (17.5\%) patients were initially intubated. The comorbidity of DM accounted for 100 cases (12.1\%) and 212 (25.7\%) patients received pelvic angioembolization or/and preperitoneal packing within $24 \mathrm{~h}$ following admission (Table 2). The mean LOS in the ICU and hospital was $11.9 \pm 16$ days (mean \pm standard deviation [SD]), and $18.1 \pm 19.6$ days (mean $\pm \mathrm{SD}$ ), respectively. The overall and early mortality rates within $48 \mathrm{~h}$ were $5.5 \%$ (45 patients) and 3.9\% (32 patients), respectively (Table 3 ). The complication rate was $16.4 \%$, with the most common being respiratory failure, accounting for $9.9 \%$ of all patients. The mean ISS score of patients with pelvic ring fracture was 18.4, which was higher (mean value: 12.5) than that of all trauma patients (ISS $\geq 5$ ) during the 10-year period ( $p<$ 0.01) (Fig. 2).

The patients who required preperitoneal packing were at higher risk of mortality (OR 36.19; 95\% CI 11.52$113.67 ; p<0.0001)$ than those who needed angioembolization (OR 4.23; 95\% CI 2.06-8.68; $p<0.0001$ ) (Table 4). The patients who received both preperitoneal packing and 
Table 1 Characteristics of patients (aged $>16$ years) with pelvic ring fractures (ISS $\geq 5$ ) at CMUH from 2008 to 2017

\begin{tabular}{|c|c|c|}
\hline \multirow[b]{2}{*}{ Characteristics } & \multicolumn{2}{|c|}{$\begin{array}{l}\text { Pelvic ring injuries } \\
n=825\end{array}$} \\
\hline & $n$ & $\%$ \\
\hline \multicolumn{3}{|l|}{ Age (years) } \\
\hline $16-25$ & 165 & 20.0 \\
\hline $26-45$ & 243 & 29.5 \\
\hline $46-65$ & 261 & 31.6 \\
\hline $66-75$ & 80 & 9.7 \\
\hline$>75$ & 76 & 9.2 \\
\hline Male sex & 456 & 55.3 \\
\hline From Referral & 375 & 45.5 \\
\hline \multicolumn{3}{|l|}{ ED GCS score } \\
\hline$>8$ & 732 & 88.7 \\
\hline$\leq 8$ & 93 & 11.3 \\
\hline \multicolumn{3}{|l|}{ ED GCS motor score } \\
\hline 6 & 686 & 83.2 \\
\hline $5-2$ & 95 & 11.5 \\
\hline 1 & 44 & 5.3 \\
\hline \multicolumn{3}{|l|}{ ISS } \\
\hline $5-15$ & 425 & 51.5 \\
\hline $16-24$ & 175 & 21.2 \\
\hline $25-35$ & 158 & 19.2 \\
\hline$>35$ & 67 & 8.1 \\
\hline \multicolumn{3}{|l|}{ AlS } \\
\hline Head/neck score > 2 & 166 & 20.1 \\
\hline Chest score $>2$ & 231 & 28.0 \\
\hline Abdomen score > 2 & 164 & 19.9 \\
\hline Extremity score $>2$ & 576 & 69.8 \\
\hline \multicolumn{3}{|l|}{ Intubated } \\
\hline None & 681 & 82.5 \\
\hline In other hospital & 41 & 5.0 \\
\hline In our hospital & 103 & 12.5 \\
\hline \multicolumn{3}{|l|}{ ED systolic blood pressure } \\
\hline$>90 \mathrm{mmHg}$ & 723 & 87.6 \\
\hline $61-90$ mmHg & 87 & 10.6 \\
\hline$\leq 60 \mathrm{mmHg}$ & 10 & 1.2 \\
\hline Missing & 5 & 0.6 \\
\hline \multicolumn{3}{|l|}{ ED pulse } \\
\hline $51-120$ bpm & 733 & 88.8 \\
\hline > 120 bpm & 80 & 9.7 \\
\hline 0-50 bpm & 7 & 0.9 \\
\hline Missing & 5 & 0.6 \\
\hline DM & 100 & 12.1 \\
\hline
\end{tabular}

Table 2 In-hospital processing measures

\begin{tabular}{llc}
\hline & \multicolumn{2}{l}{ Pelvic ring injuries } \\
\cline { 2 - 3 } Process measures & $n$ & $\%$ \\
\hline Nonoperative & 613 & 74.3 \\
Angioembolization & 182 & 22.1 \\
Preperitoneal packing & 13 & 1.6 \\
Angioembolization + preperitoneal packing & 17 & 2.1 \\
ICU & 137 & 16.6 \\
Operating room & 415 & 50.3 \\
ICU LOS, mean \pm SD & & $11.9 \pm 16.0$ \\
Hospital LOS, mean \pm SD & & $18.1 \pm 19.6$ \\
\hline
\end{tabular}

angioembolization were at the highest risk of complications (OR 6.96; 95\% CI 2.96-16.38; $p<0.0001$ ). The risk of mortality included initial vital signs with GCS $\leq 8$ (OR 3.87, 95\% CI 1.57-9.58, $p<0.0001$ ), systolic blood pressure $(\mathrm{SBP}) \leq 60 \mathrm{mmHg}$ (OR 9.48; 95\% CI 1.85-48.52; $p<$ 0.0001 ), and pulse rate $0-50 \mathrm{bpm}$ (OR 11.54; $95 \% \mathrm{CI}$ 1.21-109.6; $p<0.0001$ ) (Table 5). The risk of complications included initial vital signs, with $60<\mathrm{SBP}<90$ $\mathrm{mmHg}$ (OR 2.23.19; 95\% CI 1.29-3.86; $p<0.0001$ ) and pulse rate $>120 \mathrm{bpm}$ (OR 1.91; 95\% CI 1.07-3.44, $p<$ $0.0001)$. Higher ISS score was also related to higher rates of mortality (ISS > 35; OR 47.56; 95\% CI 6.83-331.1; $p<$ 0.0001 ) and complications (ISS > 35; OR 14.33; $95 \%$ CI $5.13-40.0 ; p<0.0001)$. In contrast, individual AIS involvement was not linked to higher rates of mortality or complications. Notably, the comorbidity of DM was related to a higher rate of mortality (OR 3.18; 95\% CI 1.10-9.21; $p<$ 0.0001). In addition, higher ISS scores were also related to

Table 3 Number of deaths and adverse events among patients with pelvic ring fractures between 2008 and 2017

\begin{tabular}{lll}
\hline \multirow{2}{*}{ Outcomes } & \multicolumn{2}{l}{ Pelvic ring injuries } \\
\cline { 2 - 3 } Mortality & $n$ & $\%$ \\
Early mortality $(<48 \mathrm{~h})$ & 32 & 3.5 \\
Complications & 135 & 16.4 \\
Respiratory failure & 82 & 9.9 \\
Pulmonary edema & 5 & 0.6 \\
ARDS & 8 & 1.0 \\
Pneumonia & 27 & 3.3 \\
Gl bleed & 12 & 1.5 \\
Acute renal failure & 7 & 0.9 \\
UTI & 31 & 3.8 \\
Compartment syndrome (extremity) & 1 & 0.1 \\
Osteomyelitis & 1 & 0.1 \\
Other infection (sepsis, bacteremia, etc.) & 18 & 2.2 \\
\hline
\end{tabular}




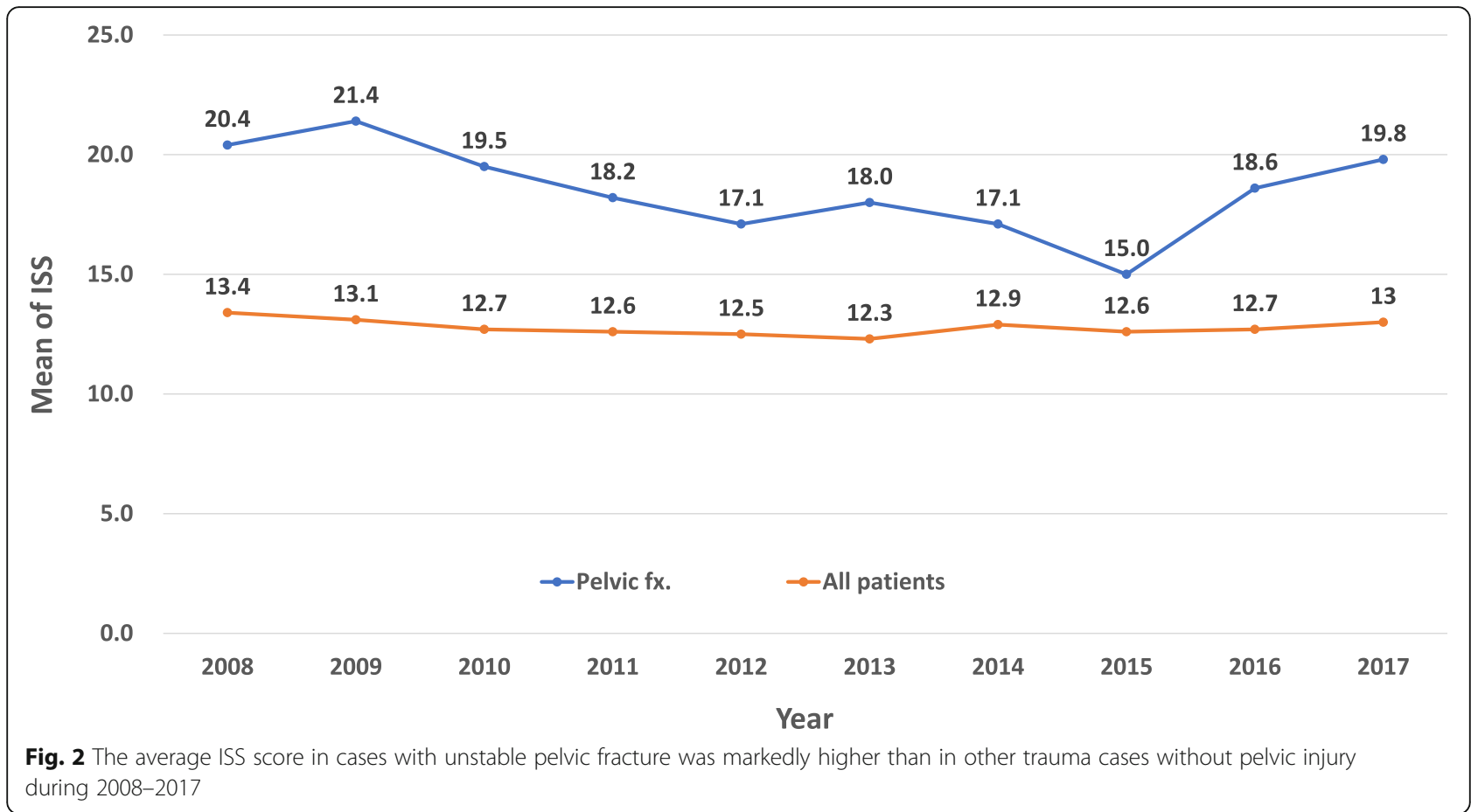

longer ICU stay and hospitalization (Table 6). An AIS head/neck involvement score $>2$ indicated longer stay in the ICU.

Following the application of the institutional clinical protocol for the management of traumatic pelvic ring fracture, the rate of mortality declined annually, from $7.8 \%$ in 2008 to $2.4 \%$ in 2017 ( $p$ for trend < 0.05) (Fig. 3). The trends of annual mortality of pelvic fracture with ISS $\geq 16$ declined from 14.3 to $2.0 \%$ over a 10 -year period ( $p$ for trend $=0.032$ ). The mean mortality of pelvic fracture patient with ISS $\geq 16$ was $10.8 \%$. There was no statistically significant difference in the average 10year mortality rate between patients with unstable pelvic fracture $(5.5 \%)$ and those with other trauma (whose ISS $\geq 5$ ) without pelvic fracture (3.6\%; $p=0.0587$ ) (Fig. 3). According to the algorithm for traumatic pelvic ring fracture, there were two indications for emergent stable vital signs, namely contrast extravasation on computed tomography scan (62 patients; $73.8 \%$ ) and unstable hemodynamics without other cavitary or external bleeding (22 patients; 26.2\%). In our hospital, there is an interventional radiology team on-call for $24 \mathrm{~h}$ per day. The average time to transarterial embolization (TAE) in our study was $62.0 \pm 33.4$ min (mean $\pm \mathrm{SD})$, with 47 patients $(56 \%)$ receiving TAE within $1 \mathrm{~h}$. In our study, $22 \%$ of cases underwent selective embolization, without occurrence of complications in the entire study population.

\section{Discussion}

In this study, we identified the presence of unstable initial vital signs (i.e., SBP $<90 \mathrm{mmHg}, \mathrm{GCS}<9$, ISS $>15$, pulse rate $<50 \mathrm{bpm})$ and $\mathrm{DM}$ as significant risk factors for mortality or complications in patients with pelvic fracture. We also found an overall OR of 2.0 for the effect of a pelvic fracture on the rate of mortality. The most common type of complication was respiratory complications.

Table 4 Simple logistic regression for initial treatment, mortality, and complications

\begin{tabular}{|c|c|c|c|c|c|c|}
\hline \multirow[b]{2}{*}{ Variable } & \multicolumn{3}{|c|}{ Mortality (yes vs. no) } & \multicolumn{3}{|c|}{ Complication (yes vs. no) } \\
\hline & OR & $95 \% \mathrm{Cl}$ & $p$ & OR & $95 \% \mathrm{Cl}$ & $p$ \\
\hline Treatment & & & $<0.0001$ & & & $<0.0001$ \\
\hline Nonoperative & 1.00 & Reference & & 1.00 & Reference & \\
\hline Angioembolization & 4.23 & $2.06-8.68^{*}$ & & 2.57 & $1.70-3.87^{*}$ & \\
\hline Preperitoneal packing & 36.19 & $11.52-113.67^{*}$ & & 5.06 & $1.75-14.66^{*}$ & \\
\hline Angioembolization + preperitoneal packing & 14.60 & $5.00-42.60^{*}$ & & 6.96 & $2.96-16.38^{*}$ & \\
\hline
\end{tabular}

*There is significant difference $p<0.0001$ 
Table 5 Multiple logistic regression for patient characteristics, mortality, and complications

\begin{tabular}{|c|c|c|c|c|}
\hline \multirow[b]{2}{*}{ Variable } & \multicolumn{2}{|c|}{ Mortality (yes vs. no) } & \multicolumn{2}{|c|}{ Complication (yes vs. no) } \\
\hline & OR & $95 \% \mathrm{Cl}$ & OR & $95 \% \mathrm{Cl}$ \\
\hline \multicolumn{5}{|l|}{ ED GCS } \\
\hline$>8$ & 1.00 & Reference & 1.00 & Reference \\
\hline$\leq 8$ & 3.87 & $1.57-9.58^{*}$ & 1.67 & $0.91-3.08$ \\
\hline \multicolumn{5}{|l|}{ ED SBP } \\
\hline$>90 \mathrm{mmHg}$ & 1.00 & Reference & 1.00 & Reference \\
\hline $61-90 \mathrm{mmHg}$ & 2.53 & $1.11-5.73^{*}$ & 2.23 & $1.29-3.86^{*}$ \\
\hline$\leq 60 \mathrm{mmHg}$ & 9.48 & $1.85-48.52^{*}$ & 0.92 & $0.21-4.06$ \\
\hline \multicolumn{5}{|l|}{ ED pulse } \\
\hline $51-120 \mathrm{bpm}$ & 1.00 & Reference & 1.00 & Reference \\
\hline$>120 \mathrm{bpm}$ & 0.81 & $0.32-2.03$ & 1.91 & $1.07-3.44^{*}$ \\
\hline $0-50$ bpm & 11.54 & $1.21-109.6^{*}$ & - & - \\
\hline \multicolumn{5}{|l|}{ DM } \\
\hline No & 1.00 & Reference & 1.00 & Reference \\
\hline Yes & 3.18 & $1.10-9.21^{*}$ & 1.62 & $0.87-3.03$ \\
\hline \multicolumn{5}{|l|}{ ISS } \\
\hline $5-15$ & 1.00 & Reference & 1.00 & Reference \\
\hline $16-24$ & 4.84 & $0.85-27.65^{*}$ & 2.66 & $1.38-5.14^{*}$ \\
\hline $25-35$ & 11.97 & $2.09-68.64^{*}$ & 6.23 & $2.87-13.5^{*}$ \\
\hline$>35$ & 47.56 & $6.83-331.1^{*}$ & 14.33 & $5.13-40.0^{*}$ \\
\hline \multicolumn{5}{|l|}{ AIS } \\
\hline \multicolumn{5}{|c|}{ Head/neck score $>2$} \\
\hline No & 1.00 & Reference & 1.00 & Reference \\
\hline Yes & 0.87 & $0.34-2.26$ & 1.09 & $0.61-1.96$ \\
\hline \multicolumn{5}{|c|}{ Chest score $>2$} \\
\hline No & 1.00 & Reference & 1.00 & Reference \\
\hline Yes & 0.66 & $0.28-1.56$ & 0.52 & $0.30-0.92^{*}$ \\
\hline \multicolumn{5}{|c|}{ Abdomen score $>2$} \\
\hline No & 1.00 & Reference & 1.00 & Reference \\
\hline Yes & 1.63 & $0.67-3.94$ & 1.07 & $0.61-1.86$ \\
\hline \multicolumn{5}{|c|}{ Extremity score $>2$} \\
\hline No & 1.00 & Reference & 1.00 & Reference \\
\hline Yes & 1.26 & $0.46-3.49$ & 1.13 & $0.66-1.94$ \\
\hline
\end{tabular}

*There is significant difference $p<0.0001$

Hemorrhage is considered the leading cause of death in patients with pelvic ring injuries $[5,19,20]$. Lustenberger et al. examined trauma registry reports comparing 3296 patients with pelvic fracture and 59,737 patients without pelvic fracture. Their univariate analysis revealed that the OR of pelvic fracture for mortality was 2.4, which is consistent with our result (OR 2.0) [21]. Some studies suggested brain injuries as the major cause of death in patients with pelvic ring fracture [22-24]. Further investigation demonstrated that isolated pelvic fractures were rarely lethal injuries, while a combination of pelvic and abdominal or thoracic injury resulted in a fatal course [5]. Consequently, we compared the combination injury as assessed using different systems. Our data show that pelvic injuries are linked to a higher mortality rate than other kinds of injuries. In our 10-year analysis, we did not identify any specific association with a single injury type; however, the severity of combined ISS appears to increase the rate of mortality in patients with pelvic trauma. Therefore, in cases with pelvic injuries, injuries at other sites should also be assessed, and a multidisciplinary approach should be taken in the initial assessment and in preventing secondary injuries. The comorbidity of DM contributed to a higher mortality rate. DM may increase the rates of mortality and complications in cases with pelvic trauma through multiple mechanisms. Patients with diabetes who sustain trauma experience higher rates of complications and utilization of resources [11, 12].

During the analyses period of 10 years, the rate of mortality and mean LOS in patients with complex pelvic fracture in our institution was 5.5\% and 18.1 days, respectively. These data are consistent with those of another population-based study conducted in Taiwan. Yang et al. reported a 12-year (2000-2011) Taiwanese nationwide health insurance database study [25]. The mean case-fatality rate was $2.1 \%$ and $1.6 \%$ in male and female patients, respectively; the mean LOS for complex pelvic fracture was 17.9 days. As a level I trauma center in Taiwan, $45.5 \%$ of our cases were transferred from other hospitals. The mean ISS score in our ED cases was higher than that reported in other hospitals in Taiwan, which may explain the higher mortality rates $[5,26]$. The annual mortality rate declined from $7.8 \%$ in 2008 to $2.4 \%$ in $2017(p<0.001)$. This rate is in line with data obtained from other contemporary studies $[8,26]$ and lower than that reported in a previous study (overall mortality $7.7 \%$ ) performed in another level I trauma center [27].

With recent improvements in pre-hospital management and standardized treatment protocols for the treatment of shock, several studies have shown a decreasing mortality rate among trauma patients with pelvic fractures [8-16]. Previous studies have investigated initial treatments for the management of hemorrhage, including temporary pelvic fracture stabilization, AE, PPP and Resuscitative Endovascular Balloon Occlusion of the Aorta (REBOA) [28-36].

Pelvic bleeding is the result of disruption of the presacral venous plexus and bone. Our protocol emphasizes the early implementation of the Advanced Trauma Life Support guideline, as well as the usage of focused assessment with sonography in trauma (FAST), to detect lifethreatening signs and ensure timely intervention for 
Table 6 Simple linear regression analysis for total hospital LOS (length of stay) and ICU LOS

\begin{tabular}{|c|c|c|c|c|c|c|}
\hline & \multicolumn{3}{|l|}{$\begin{array}{l}\text { Hospital LOS } \\
(n=825)\end{array}$} & \multicolumn{3}{|l|}{$\begin{array}{l}\text { ICU LOS } \\
(n=362) \\
\end{array}$} \\
\hline & Coefficient & SE & $p$ & Coefficient & SE & p \\
\hline ISS (vs. 5-15) & & & $<0.0001$ & & & $<0.0001$ \\
\hline $16-24$ & 9.27 & 1.59 & & 2.95 & 2.49 & \\
\hline $25-35$ & 16.90 & 1.65 & & 7.46 & 2.35 & \\
\hline$>35$ & 24.37 & 2.33 & & 13.68 & 2.76 & \\
\hline \multicolumn{7}{|l|}{ AIS } \\
\hline Head/neck score $>2($ vs. $\leq 2)$ & 11.88 & 1.65 & $<0.0001$ & 5.52 & 1.73 & 0.0016 \\
\hline Chest score > 2 (vs. $\leq 2$ ) & 6.67 & 1.50 & $<0.0001$ & 0.64 & 1.69 & 0.7098 \\
\hline Abdomen score > 2 (vs. $\leq 2)$ & 10.54 & 1.67 & $<0.0001$ & 0.99 & 1.83 & 0.5898 \\
\hline Extremity score > 2 (vs. $\leq 2)$ & 2.14 & 1.48 & $<0.0001$ & 1.59 & 1.81 & 0.3820 \\
\hline
\end{tabular}

hemostasis and resuscitation. Approximately $85 \%$ of pelvic fracture hemorrhages are caused by bone and venous bleeding [16, 37]. Therefore, temporary mechanical stabilization methods, such as circumferential sheet wrapping and pelvic packing, are necessary to control bleeding [38-40].

The selection of an external skeletal fixator or a circumferential compression sling/binder device for acute temporary stabilization in pelvic injury remains debatable. In our institution, we use a circumferential compression device/sling as the first choice, as recommended by numerous guidelines (i.e., Advanced Trauma Life Support [41], Eastern Association for the Surgery of Trauma [42],
Western Trauma Association [43], and The American College of Surgeons Trauma Quality Improvement Program [44]). Anterior pelvic external fixation is indicated in patients with unstable antero-posterior compression and lateral compression injuries by the Young-Burgess fracture classification [45]. C-clamp is used in cases with stabilized posterior pelvic ring disruption to control hemorrhage, especially in patients with vertical unstable pelvic injury [21]. The Young-Burgess system has been shown to predict mortality [40]; however, there is currently a gap in interobserver reliability in the classification systems of pelvic ring fractures [39]. Moreover, use of the posterior C-clamp is contraindicated in comminuted and

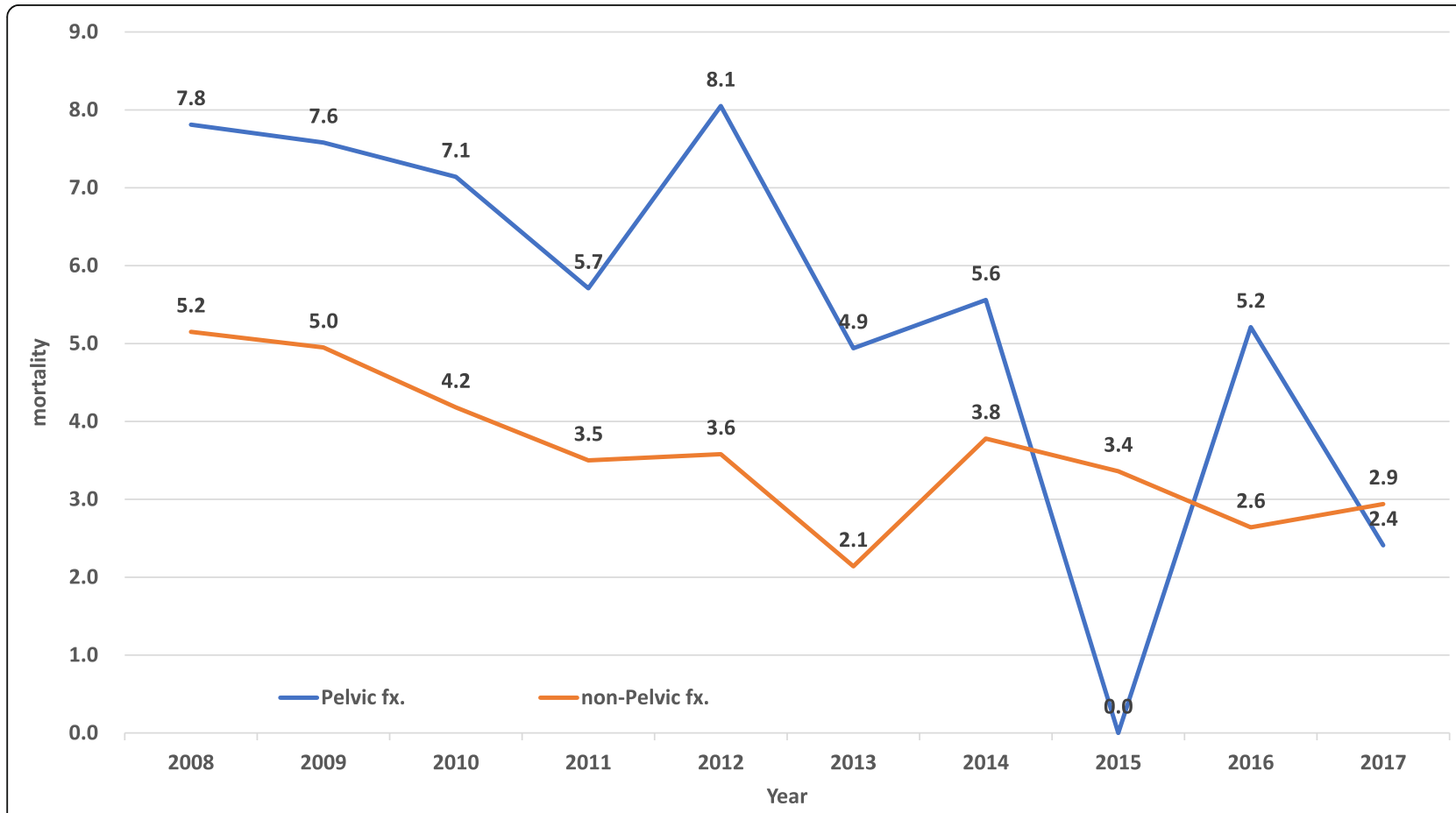

Fig. 3 The trends of annual mortality declined from $7.8 \%$ to $2.4 \%$ over a 10-year period ( $p$ for trend $<0.05$ ) 
transforaminal sacral fractures, fractures of the iliac wing, and lateral compression-type injuries [46]. Therefore, training is required for the selection of the most appropriate external fixation for a particular type fracture. Our system incorporates fewer external pelvic fixations owing to the learning curve of the technique and the need for experience to avoid complications from pin placement.

$\mathrm{AE}, \mathrm{REBOA}$, and PPP were effective in controlling hemorrhage [30, 31, 33-36, 47-54]. However, these procedures have been associated with complications such as wound complication in PPP [32, 47, 55], and gluteal muscle necrosis, nerve injury bladder, or ureteral infarction after $\mathrm{AE}[31,37,48,56,57]$, and acute kidney injury, vascular complications in REBOA [58]. Therefore, the optimal management algorithm for the management of hemodynamically unstable patients with pelvic fractures remains controversial. Based on recent literature, the two most common algorithms for the treatment of patients with persistent hemodynamic instability were early AE or early PPP with selective AE [29, 32, 47, 59]. The timing of the procedure is the key for successful intervention and improved survival [35, 36, 59]. The guideline established by the World Society of Emergency Surgery [10] recommends PPP as first-line therapy; however, this recommendation is inconsistent across guidelines [35, 41, 42, 44]. In our institutional guideline, failure of fluid resuscitation and circumferential compression device/sling in the initial stage was followed by application of early TAE. The role of PPP in our protocol was application in case of hemodynamic instability and the unavailability or failure of interventional radiology. In our study, $\mathrm{AE}$ effectively controlled hemorrhage, in line with other reports [22, 31, 50, 52]. These results are consistent with those of other investigations; patients who received both TAE and PPP had a higher rate of complications than those receiving another procedure alone [30].

The strength of our study is the long-term detailed database of a level I trauma center, which provided complete data (e.g., initial vital signs, management, length of stay to the ICU, complications, and mortality).

Our results suggest that the pelvic fracture itself should not be considered a fatal fracture as previously described. This statement is also consistent with the conclusion of a post-mortem analysis of 655 patients with pelvic fracture trauma performed by Papadopoulos et al., which suggested that only $3.5 \%$ of deaths are directly related to actual pelvic fractures [60]. Our findings indicate that pelvic fracture mortality is subject to a number of confounding factors (especially when part of AIS).

Our study had several limitations. Firstly, there was an inherent selection bias owing to the retrospective design of the study. Secondly, patients without hospital cardiac arrest and declared death at the accident were not included in our hospital trauma registered database, which could lead to bias. Thirdly, this was a single-center database analysis, limited to a single level I trauma center; hence, the findings may not be representative of other populations in other areas. Fourth, REBOA is a bridge to time-consuming procedures. However, as REBOA is not authorized by the Taiwan Food and Drug Administration, we would not be able to compare the effect of REBOA with other methods in our study. Finally, the study design did not include a control group. However, the development of a randomized controlled clinical trial to prove superiority of certain procedures over others in this critical injury setting is challenging.

\section{Conclusion}

The results of our study demonstrated that initial vital signs, ISS, GCS, and DM are associated with a high rate of mortality. Based on our 10 years of experience, the mortality rate was reduced through institutional efforts toward the application of guidelines for the initial management of pelvic fracture.

\section{Abbreviations \\ AIS: Abbreviated injury scale; ED: Emergency department; FAST: Focused assessment with sonography in trauma; GCS: Glasgow Coma Scale; ICU: Intensive care unit; ISS: Injury Severity Score; LOS: Length of stay; PPP: Preperitoneal pelvic packing; REBOA: Resuscitative Endovascular Balloon Occlusion of the Aorta; SBP: Systolic blood pressure; TAE: Transcatheter arterial embolization}

\section{Acknowledgements}

This study was supported in part by the Taiwan Ministry of Health and Welfare Clinical Trial Center (MOHW108-TDU-B-212-133004). We would like to thank Uni-edit (www.uni-edit.net) for editing and proofreading this manuscript.

\section{Authors' contributions}

C-HT, W-YC, W-SC, and T-CH contributed to the study conception and design. W-YC, W-SC, and S-LT contributed to the acquisition of the data. L-YS, $\mathrm{C}-\mathrm{CC}, \mathrm{C}-\mathrm{HT}$, and T-CH contributed to the analysis and interpretation of the data. C-HT, S-LT, H-CC, and T-CH contributed to the drafting of the manuscript. T-CH contributed to the critical revision. All authors read and approved the final manuscript.

Funding

No commercial associations with or sources of support from any funding agency.

\section{Availability of data and materials}

Not applicable

Ethics approval and consent to participate

This retrospective study was approved by the Institutional of Review Board of China Medical University Hospital (CMUH104-REC2-115).

Consent for publication

All authors agreed to the publication of this article.

Competing interests

The authors declare that they have no competing interests.

\section{Author details}

'Department of Orthopedic Surgery, China Medical University Hospital, Taichung, Taiwan. ${ }^{2}$ Spine Center, China Medical University Hospital, China Medical University, Taichung, Taiwan. ${ }^{3}$ Department of Sports Medicine, College of Health Care, China Medical University, Taichung, Taiwan. 
${ }^{4}$ Department of Surgery, China Medical University Hospital, Taichung, Taiwan. ${ }^{5}$ Department of Surgery, School of Medicine, China Medical University, Taichung, Taiwan. ${ }^{6}$ Division of Emergency Disease Surgery, China Medical University Hospital, Taichung, Taiwan. ${ }^{7}$ Department of Orthopedic Surgery, School of Medicine, China Medical University, \#91 Hsueh-Shih Road, Taichung 404, Taiwan.

\section{Received: 29 October 2019 Accepted: 16 December 2019}

\section{Published online: 27 December 2019}

\section{References}

1. Durkin A, Sagi HC, Durham R, Flint L. Contemporary management of pelvic fractures. Am J Surg. 2006;192(2):211-23.

2. Court-Brown CM, Caesar B. Epidemiology of adult fractures: a review. Injury. 2006;37(8):691-7.

3. Khanna P, Phan H, Hardy AH, Nolan T, Dong P. Multidisciplinary management of blunt pelvic trauma. Semin Intervent Radiol. 2012;29(3): 187-91.

4. Demetriades D, Karaiskakis M, Toutouzas K, Alo K, Velmahos G, Chan L. Pelvic fractures: epidemiology and predictors of associated abdominal injuries and outcomes1 1 No competing interests declared. J Am Coll Surgeons. 2002;195(1):1-10.

5. Holstein $\mathrm{JH}$, Culemann U, Pohlemann T. What are predictors of mortality in patients with pelvic fractures? Clin Orthop Relat Res. 2012;470(8):2090-7.

6. Giannoudis PV, Grotz MR, Tzioupis C, Dinopoulos H, Wells GE, Bouamra O, Lecky F. Prevalence of pelvic fractures, associated injuries, and mortality: the United Kingdom perspective. J Trauma. 2007;63(4):875-83.

7. Bakhshayesh P, Weidenhielm L, Enocson A. Factors affecting mortality and reoperations in high-energy pelvic fractures. Eur J Orthop Surg Traumatol. 2018;28(7):1273-82.

8. Black SR, Sathy AK, Jo C, Wiley MR, Minei JP, Starr AJ. Improved survival after pelvic fracture: 13-year experience at a single trauma center using a multidisciplinary institutional protocol. J Orthop Trauma. 2016;30(1):22-8.

9. Biffl WL, Smith WR, Moore EE, Gonzalez RJ, Morgan SJ, Hennessey T, Offner PJ, Ray CE Jr, Franciose RJ, Burch JM. Evolution of a multidisciplinary clinical pathway for the management of unstable patients with pelvic fractures. Ann Surg. 2001;233(6):843-50.

10. Coccolini F, Stahel PF, Montori G, Biffl W, Horer TM, Catena F, Kluger Y, Moore EE, Peitzman AB, Ivatury $R$, et al. Pelvic trauma: WSES classification and guidelines. World J Emerg Surg. 2017;12:5.

11. Burgess AR, Eastridge BJ, Young JW, Ellison TS, Ellison PS Jr, Poka A, Bathon $\mathrm{GH}$, Brumback RJ. Pelvic ring disruptions: effective classification system and treatment protocols. J Trauma. 1990;30(7):848-56.

12. Bassam D, Cephas GA, Ferguson KA, Beard LN, Young JS. A protocol for the initial management of unstable pelvic fractures. Am Surg. 1998;64(9):862-7.

13. Ghaemmaghami V, Sperry J, Gunst M, Friese R, Starr A, Frankel H, Gentilello $L M$, Shafi S. Effects of early use of external pelvic compression on transfusion requirements and mortality in pelvic fractures. Am J Surg. 2007; 194(6):720-3 discussion 3.

14. Toth L, King KL, McGrath B, Balogh ZJ. Factors associated with pelvic fracture-related arterial bleeding during trauma resuscitation: a prospective clinical study. J Orthop Trauma. 2014;28(9):489-95.

15. Magnone S, Coccolini F, Manfredi R, Piazzalunga D, Agazzi R, Arici C, Barozzi M, Bellanova G, Belluati A, Berlot $G$, et al. Management of hemodynamically unstable pelvic trauma: results of the first Italian consensus conference (cooperative guidelines of the Italian Society of Surgery, the Italian Association of Hospital Surgeons, the Multi-specialist Italian Society of Young Surgeons, the Italian Society of Emergency Surgery and Trauma, the Italian Society of Anesthesia, Analgesia, Resuscitation and Intensive Care, the Italian Society of Orthopaedics and Traumatology, the Italian Society of Emergency Medicine, the Italian Society of Medical Radiology -Section of Vascular and Interventional Radiology- and the World Society of Emergency Surgery). World J Emerg Surg. 2014;9(1):18.

16. Balogh Z, Caldwell E, Heetveld M, D'Amours S, Schlaphoff G, Harris I, Sugrue $M$. Institutional practice guidelines on management of pelvic fracturerelated hemodynamic instability: do they make a difference? J Trauma. 2005;58(4):778-82.

17. Tsai $\mathrm{CH}$, Fong $\mathrm{YC}$, Chen $\mathrm{YH}, \mathrm{Hsu} \mathrm{CJ}$, Chang $\mathrm{CH}$, Hsu HC. The epidemiology of traumatic humeral shaft fractures in Taiwan. Int Orthop. 2009;33(2):463-7.

18. Kuo PJ, Wu SC, Chien PC, Chang SS, Rau CS, Tai HL, Peng SH, Lin YC, Chen $Y C$, Hsieh HY, et al. Artificial neural network approach to predict surgical site infection after free-flap reconstruction in patients receiving surgery for head and neck cancer. Oncotarget. 2018:9(17):13768-82.

19. Papakostidis C, Giannoudis PV. Pelvic ring injuries with haemodynamic instability: efficacy of pelvic packing, a systematic review. Injury. 2009;40: S53-61.

20. Costantini TW, Coimbra R, Holcomb JB, Podbielski JM, Catalano R, Blackburn A, Scalea TM, Stein DM, Williams L, Conflitti J, et al. Current management of hemorrhage from severe pelvic fractures: results of an American Association for the Surgery of Trauma multi-institutional trial. J Trauma Acute Care Surg. 2016;80(5):717-23 discussion 23-5.

21. Lustenberger T, Meier C, Benninger E, Lenzlinger PM, Keel MJ. C-clamp and pelvic packing for control of hemorrhage in patients with pelvic ring disruption. J Emerg Trauma Shock. 2011;4(4):477-82.

22. Poole GV, Ward EF, Muakkassa FF, Hsu HS, Griswold JA, Rhodes RS. Pelvic fracture from major blunt trauma. Outcome is determined by associated injuries. Ann Surg. 1991;213(6):532-8 discussion 8-9.

23. Poole GV, Ward EF. Causes of mortality in patients with pelvic fractures. Orthopedics. 1994;17(8):691-6.

24. Gustavo Parreira J, Coimbra R, Rasslan S, Oliveira A, Fregoneze M, Mercadante $\mathrm{M}$. The role of associated injuries on outcome of blunt trauma patients sustaining pelvic fractures. Injury. 2000;31(9):677-82.

25. Yang NP, Chan CL, Chu D, Lin YZ, Lin KB, Yu CS, Yu IL, Chang NT. Epidemiology of hospitalized traumatic pelvic fractures and their combined injuries in Taiwan: 2000-2011 National Health Insurance data surveillance. Biomed Res Int. 2014;2014:878601.

26. Chiang W-K, Huang S-T, Chang W-H, Huang M-Y, Chien D-K, Tsai C-H. Mortality factors regarding the injury severity score in elderly trauma patients. Int J Gerontol. 2012;6(3):192-5.

27. Buller $L T$, Best $M J$, Quinnan SM. A nationwide analysis of pelvic ring fractures: incidence and trends in treatment, length of stay, and mortality. Geriatr Orthop Surg Rehabil. 2016;7(1):9-17.

28. Oliphant BW, Tignanelli CJ, Napolitano LM, Goulet JA, Hemmila MR. American College of Surgeons Committee on Trauma verification level affects trauma center management of pelvic ring injuries and patient mortality. J Trauma Acute Care Surg. 2019;86(1):1-10.

29. Suzuki T, Smith WR, Moore EE. Pelvic packing or angiography: competitive or complementary? Injury. 2009;40(4):343-53.

30. Filiberto DM, Fox AD. Preperitoneal pelvic packing: technique and outcomes. Int J Surg. 2016;33(Pt B):222-4.

31. Salcedo ES, Brown IE, Corwin MT, Galante JM. Pelvic angioembolization in trauma - Indications and outcomes. Int J Surg. 2016;33(Pt B):231-6.

32. Burlew CC, Moore EE, Smith WR, Johnson JL, Biffl WL, Barnett CC, Stahel PF. Preperitoneal pelvic packing/external fixation with secondary angioembolization: optimal care for life-threatening hemorrhage from unstable pelvic fractures. J Am Coll Surg. 2011;212(4):628-35.

33. Biffl WL, Fox CJ, Moore EE. The role of REBOA in the control of exsanguinating torso hemorrhage. J Trauma Acute Care Surg. 2015;78(5): 1054-8.

34. Chiara O, di Fratta E, Mariani A, Michaela B, Prestini L, Sammartano F, Cimbanassi S. Efficacy of extra-peritoneal pelvic packing in hemodynamically unstable pelvic fractures, a Propensity Score Analysis. World J Emerg Surg. 2016;11:22.

35. Blondeau B, Orlando A, Jarvis S, Banton K, Berg GM, Patel N, Meinig R Tanner A 2nd, Carrick M, Bar-Or D. Variability in pelvic packing practices for hemodynamically unstable pelvic fractures at US level 1 trauma centers. Patient Saf Surg. 2019;13:3.

36. Jarvis S, Orlando A, Blondeau B, Banton K, Reynolds C, Berg GM, Patel N, Kelly $\mathrm{M}$, Carrick M, Bar-Or D. Variability in the timeliness of interventional radiology availability for angioembolization of hemodynamically unstable pelvic fractures: a prospective survey among U.S. level I trauma centers. Patient Saf Surg. 2019;13:23.

37. Jain S, Bleibleh S, Marciniak J, Pace A. A national survey of United Kingdom trauma units on the use of pelvic binders. Int Orthop. 2013;37(7):1335-9.

38. Ooi CK, Goh HK, Tay SY, Phua DH. Patients with pelvic fracture: what factors are associated with mortality? Int J Emerg Med. 2010;3(4):299-304.

39. Koo H, Leveridge M, Thompson C, Zdero R, Bhandari M, Kreder HJ, Stephen $D$, McKee MD, Schemitsch EH. Interobserver reliability of the young-burgess and tile classification systems for fractures of the pelvic ring. J Orthop Trauma. 2008;22(6):379-84.

40. Manson T, O'Toole RV, Whitney A, Duggan B, Sciadini M, Nascone J. YoungBurgess classification of pelvic ring fractures: does it predict mortality, 
transfusion requirements, and non-orthopaedic injuries? J Orthop Trauma. 2010;24(10):603-9.

41. ATLS Subcommittee, American College of Surgeons' Committee on Trauma, International ATLS working group. Advanced trauma life support (ATLS`): the ninth edition. J Trauma Acute Care Surg. 2013;74(5):1363-6.

42. Cullinane DC, Schiller HJ, Zielinski MD, Bilaniuk JW, Collier BR, Como J, Holevar M, Sabater EA, Sems SA, Vassy WM, et al. Eastern Association for the Surgery of Trauma practice management guidelines for hemorrhage in pelvic fracture--update and systematic review. J Trauma. 2011;71(6):1850-68.

43. Tran TL, Brasel KJ, Karmy-Jones R, Rowell S, Schreiber MA, Shatz DV, Albrecht RM, Cohen MJ, DeMoya MA, Biffl WL, et al. Western Trauma Association Critical Decisions in Trauma: management of pelvic fracture with hemodynamic instability-2016 updates. J Trauma Acute Care Surg. 2016;81(6):1171-4.

44. TQIP A. Best practices in the management of orthopaedic trauma. https://www. facs.org/-/media/files/quality-programs/trauma/taip/ortho guidelines.ashx.

45. Burgess A. Invited commentary: Young-Burgess classification of pelvic ring fractures: does it predict mortality, transfusion requirements, and nonorthopaedic injuries? J Orthop Trauma. 2010;24(10):609.

46. Stahel PF, Mauffrey C, Smith WR, McKean J, Hao J, Burlew CC, Moore EE. External fixation for acute pelvic ring injuries: decision making and technical options. J Trauma Acute Care Surg. 2013;75(5):882-7.

47. Tai DK, Li WH, Lee KY, Cheng M, Lee KB, Tang LF, Lai AK, Ho HF, Cheung MT. Retroperitoneal pelvic packing in the management of hemodynamically unstable pelvic fractures: a level I trauma center experience. J Trauma. 2011;71(4):E79-86.

48. Lindahl J, Handolin L, Soderlund T, Porras M, Hirvensalo E. Angiographic embolization in the treatment of arterial pelvic hemorrhage: evaluation of prognostic mortality-related factors. Eur J Trauma Emerg Surg. 2013;39(1):57-63.

49. Lumsdaine W, Weber DG, Balogh ZJ. Pelvic fracture-specific scales versus general patient reported scales for pelvic fracture outcomes: a systematic review. ANZ J Surg. 2016;86(9):687-90.

50. Azeemuddin M, Sayani R, Turab NAQ, Mustahsan SM, Hasan M, Khan DB, Mubarak F. Institutional review of hemorrhagic pelvic emergencies effectively managed with percutaneous arterial embolization. Cureus. 2018;10(2):e2194.

51. Mann SM, Banaszek D, Lajkosz K, Brogly SB, Stanojev SM, Evans C, Bardana $\mathrm{DD}$, Yach J, Hall $\mathrm{S}$. High-energy trauma patients with pelvic fractures: Management trends in Ontario. Canada. Injury. 2018;49(10):1830-40.

52. Moskowitz EE, Burlew CC, Moore EE, Pieracci FM, Fox CJ, Campion EM, Lawless RA, Cohen MJ. Preperitoneal pelvic packing is effective for hemorrhage control in open pelvic fractures. Am Surg. 2018;215(4):675-7.

53. Vaidya R, Waldron J, Scott A, Nasr K. Angiography and embolization in the management of bleeding pelvic fractures. J Am Acad Orthop Surg. 2018; 26(4):e68-76.

54. Chou CH, Wu YT, Fu CY, Liao CH, Wang SY, Bajani F, Hsieh CH. Hemostasis as soon as possible? The role of the time to angioembolization in the management of pelvic fracture. World J Emerg Surg. 2019;14:28.

55. Totterman A, Madsen JE, Skaga NO, Roise O. Extraperitoneal pelvic packing: a salvage procedure to control massive traumatic pelvic hemorrhage. J Trauma. 2007:62(4):843-52.

56. Suzuki T, Shindo M, Kataoka Y, Kobayashi I, Nishimaki H, Yamamoto S, Uchino M, Takahira N, Yokoyama K, Soma K. Clinical characteristics of pelvic fracture patients with gluteal necrosis resulting from transcatheter arterial embolization. Arch Orthop Trauma Surg. 2005;125(7):448-52.

57. Matityahu A, Marmor M, Elson JK, Lieber C, Rogalski G, Lin C, Belaye T, Miclau T 3rd, Kandemir U. Acute complications of patients with pelvic fractures after pelvic angiographic embolization. Clin Orthop Relat Res 2013;471(9):2906-11.

58. Do WS, Forte DM, Sheldon RR, Weiss JB, Barron MR, Sokol KK, Black GE, Hegge SR, Eckert MJ, Martin MJ. Preperitoneal balloon tamponade and resuscitative endovascular balloon occlusion of the aorta: alternatives to open packing for pelvic fracture-associated hemorrhage. J Trauma Acute Care Surg. 2019;87(1):18-26.

59. Osborn PM, Smith WR, Moore EE, Cothren CC, Morgan SJ, Williams AE, Stahel PF. Direct retroperitoneal pelvic packing versus pelvic angiography: a comparison of two management protocols for haemodynamically unstable pelvic fractures. Injury. 2009;40(1):54-60.

60. Papadopoulos IN, Kanakaris N, Bonovas S, Triantafillidis A, Garnavos C, Voros D, Leukidis C. Auditing 655 fatalities with pelvic fractures by autopsy as a basis to evaluate trauma care. J Am Coll Surgeons. 2006;203(1):30-43.

\section{Publisher's Note}

Springer Nature remains neutral with regard to jurisdictional claims in published maps and institutional affiliations.

Ready to submit your research? Choose BMC and benefit from:

- fast, convenient online submission

- thorough peer review by experienced researchers in your field

- rapid publication on acceptance

- support for research data, including large and complex data types

- gold Open Access which fosters wider collaboration and increased citations

- maximum visibility for your research: over $100 \mathrm{M}$ website views per year

At BMC, research is always in progress.

Learn more biomedcentral.com/submissions 